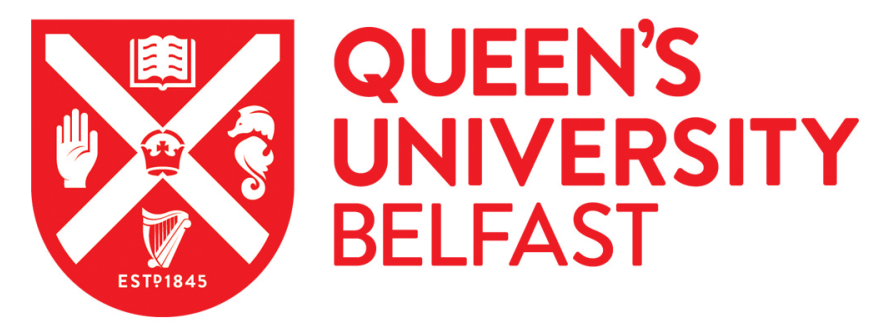

\title{
Sex hormone-binding globulin is a major determinant of the lipid profile: the PRIME Study
}

Bataille, V., Perret, B., Evans, A., Amouyel, P., Arveiler, D., Ducimetiere, P., Bard, J. M., \& Ferrieres, J. (2005). Sex hormone-binding globulin is a major determinant of the lipid profile: the PRIME Study. Atherosclerosis, 179(2), 369-373.

Published in:

Atherosclerosis

Queen's University Belfast - Research Portal:

Link to publication record in Queen's University Belfast Research Portal

\section{General rights}

Copyright for the publications made accessible via the Queen's University Belfast Research Portal is retained by the author(s) and / or other copyright owners and it is a condition of accessing these publications that users recognise and abide by the legal requirements associated with these rights.

Take down policy

The Research Portal is Queen's institutional repository that provides access to Queen's research output. Every effort has been made to ensure that content in the Research Portal does not infringe any person's rights, or applicable UK laws. If you discover content in the Research Portal that you believe breaches copyright or violates any law, please contact openaccess@qub.ac.uk. 


\title{
Sex hormone-binding globulin is a major determinant of the lipid profile: the PRIME study
}

\author{
Vincent Bataille ${ }^{\mathrm{a}}$, Bertrand Perret $^{\mathrm{b}}$, Alun Evans ${ }^{\mathrm{c}}$, Philippe Amouyel ${ }^{\mathrm{d}}$, \\ Dominique Arveiler ${ }^{\mathrm{e}}$, Pierre Ducimetière ${ }^{\mathrm{f}}$, Jean-Marie Bard ${ }^{\mathrm{g}}$, Jean Ferrières ${ }^{\mathrm{a}, *}$ \\ a INSERM U 558, Faculté de Médecine, Département d'Epidémiologie, 37, Allées Jules Guesde, 31073 Toulouse, cedex, France \\ ${ }^{\mathrm{b}}$ INSERM U563, Lipoprotein and Lipid mediators Department, CHU, Toulouse, France \\ ${ }^{\mathrm{c}}$ Department of Epidemiology and Public Health, Queen's University, Belfast, UK \\ d Pasteur Institute, Lille, France \\ e Department of Epidemiology and Public Health, Strasbourg, France \\ I INSERM U 258, Brousse Hospital, Villejuif, France \\ ${ }^{\mathrm{g}}$ The Department of Atherosclerosis, INSERM UR 545, Lille, France
}

Received 15 March 2004; received in revised form 25 October 2004; accepted 26 October 2004

Available online 21 December 2004

\begin{abstract}
The prevalence of coronary heart disease is much higher in men than in women and sex hormones might play a role in these differences through their influence on the lipid profile. The aim of this cross-sectional study was to study the relationship between hormonal markers (total testosterone (TT), estradiol (E2), sex-hormone-binding globulin (SHBG)) and plasma lipids in a population-based sample. Subjects were 352 men, 50-59 years old, selected in France (Lille, Strasbourg and Toulouse) and Northern-Ireland (Belfast) who had questionnaires and a medical examination at baseline of the PRIME prospective study (1991-1993). Pearson correlation coefficients and Student's t tests were used to identify factors associated with plasma lipids. Multiple linear regression models were used for multivariate analyses, using triglycerides (TG) (log-transformed) and high density-lipoprotein cholesterol (HDL-C) as dependent variables. SHBG and TT were negatively correlated with TG $(p<0.0001$ and $p<0.05$, respectively) and positively correlated with HDL-C $(p<0.0001$ and $p<0.01)$. E2 was positively correlated with TG $(p<0.05)$. No significant association was found between sex-hormones and LDL-C. In multiple linear regression analyses, SHBG remained independently associated negatively with TG $(p<0.01)$ and positively with HDL-C $(p<0.0001)$ after adjustment for centre of recruitment, age, body mass index, systolic blood pressure, smoking, alcohol intake and physical activity. After further adjustment for insulin, the association between SHBG and HDL-C remained highly significant $(p<0.0001)$. The association between SHBG and TG was weakened but remained also significant. Our results suggest that SHBG might to be a central protein in the hormonal regulation of the lipid profile.

(c) 2004 Elsevier Ireland Ltd. All rights reserved.
\end{abstract}

Keywords: Testosterone; Estradiol; SHBG; Lipoproteins; Insulin

\section{Introduction}

Coronary heart disease (CHD) incidence is known to be lower in women than in men [1] and differences in prevalence of major cardiovascular risk factors according to gender, including lipid abnormalities, have been found to explain part of men's higher CHD risk [2]. However, the reasons why the

\footnotetext{
* Corresponding author. Tel.: +335615218 70; fax: +33562264240.

E-mail address: jean.ferrieres@ cict.fr(J. Ferrières).
}

lipid profile is more favourable in women than in men are not completely acknowledged, and some arguments suggest that sex hormones and their regulation may have an important impact on the metabolism of blood lipids. For instance, plasma levels of high density-lipoprotein cholesterol (HDLC) in boys and girls are comparable during childhood, but at puberty, HDL-C remains unchanged in girls while it decreases in boys, concurrently with rising testosterone levels [3]. Conversely, an early menopause is known to be associated with an increased risk of CHD mortality in women [4]. 
Studies on the relationships between sex hormones and cardiovascular risk or cardiovascular risk factors in men are numerous, but their results are contradictory. Although associations between high levels of total testosterone (TT) and a beneficial lipid profile (particularly a high HDL-C) in men have been regularly reported in cross-sectional and casecontrol studies [5], sex hormones have never been shown to be predictive in prospective studies on CHD. Furthermore, most studies have focused on total levels of sex hormones and levels of sex-hormone-binding globulin (SHBG) (the specific binding protein of sex hormones in the plasma) have been too rarely evaluated even though its regulatory role might be crucial. The objective of this work was to study the association of sex hormones and SHBG with plasma lipids in middle-aged men from France and Northern-Ireland.

\section{Methods}

We have examined the associations of sex hormones (TT, estradiol (E2) and SHBG) with plasma lipoproteins and apolipoproteins (triglycerides (TG), HDL-C, low density-lipoprotein cholesterol (LDL-C), apolipoprotein A1 (ApoA1), and lipoprotein (a) (Lp(a))).

The PRIME Study [6,7] is a large prospective study conducted in France (Lille, Strasbourg and Toulouse) and Northern-Ireland (Belfast) to evaluate markers of coronary heart disease. The PRIME cohort is composed of 10592 men, aged 50-59 years and free of CHD at baseline. Subjects included in the present cross-sectional study were 352 men from a subgroup of subjects, randomly selected at baseline among participants in the PRIME Study, for whom all biological assays planned in the PRIME Study were performed at baseline.

All subjects had to answer a questionnaire administered by a trained nurse, collecting data about medical history, tobacco and alcohol consumption and physical activity. A medical examination including standardised measurements of height, weight, waist and hip circumferences and blood pressure was also performed, and a blood sample was collected for each subject. In the PRIME study, blood samples were drawn in the morning after a $12 \mathrm{~h}$-fasting period in tubes containing EDTA and centrifugation was performed immediately. Plasma samples were aliquoted for immediate analysis (total-cholesterol, HDL-C, TG, Lp(a), apolipoproteins. ..) or long-term storage for ulterior planned assays (notably insulin, TT, E2 and SHBG). Plasma for lipids analysis was sent weekly at $4{ }^{\circ} \mathrm{C}$ to the co-ordinating laboratory in Lille, others aliquots were stored locally at $-80^{\circ} \mathrm{C}$ and regularly sent to Lille. However, for the randomly selected sub-group we used to perform this cross-sectional analysis, all biological assays planned in the PRIME Study, including assays of SHBG and hormones, were performed at baseline. Plasma lipids were assayed by usual methods, except LDL-C which was computed using Planella's formula [8]. The Planella's formula was used rather than the Friedewald's formula because
Planella's LDL-cholesterol can be calculated for all subjects while the Friedewald's formula cannot be used for subjects with TG $>4.6 \mathrm{mmol} / \mathrm{l}$ ( 12 subjects in our sample). TT and E2 were assayed by radioimmunoassay (DiaSorin, SA). SHBG was assayed by electro-immuno-diffusion (Sebia, Issy-LesMoulineaux, France) and insulin was obtained by competitive radioimmunoassay (Sanofi Diagnostic Pasteur, France). HDL-C, TG, ApoA1, systolic blood pressure (SBP), SHBG, TT and E2 were used in the analyses under their continuous forms, after logarithmic transformation when their distributions were skewed (TG). Lp(a) was studied according to two classes $(<0.3 \mathrm{~g} / \mathrm{l}, \geq 0.3 \mathrm{~g} / \mathrm{l})$, and insulin was categorised according to four classes (quartiles). Physical activity was defined by an intense physical activity during at least $20 \mathrm{~min}$, at least once a week. Self reported alcohol consumption (number of glasses, detailed for each beverage and for each day of the week) was used to compute a quantity of pure alcohol ingested by day ( $\mathrm{g} / \mathrm{d})$, and was analysed according to three classes (teetotallers, $<40 \mathrm{~g} / \mathrm{d}$, $\geq 40 \mathrm{~g} / \mathrm{d}$ ). Smoking was analysed according to two classes (yes: at least one cigarette a day at the moment of the examination, no: non-smoker). Body mass index (BMI) and waist-to-hip ratio (WHR) were computed respectively as weight $(\mathrm{kg})$ divided by squared height $\left(\mathrm{m}^{2}\right)$ and waist circumference divided by hip circumference.

Data analyses were carried out using SAS Statistical Software, version 8.2 (SAS Institute Inc., Cary, NC, USA). For univariate analyses, Pearson correlation coefficients were used to test correlations between plasma lipids and sex hormones markers. Student's $t$-tests were used to study the associations of sex hormones with categorical data. Multiple linear regression models were used to investigate the relationships between sex hormones and plasma lipids after forced adjustment for centre of recruitment, age, BMI, SBP, smoking, alcohol intake and physical activity (Adjustment A). In order to study the effect of insulin on these relationships, another adjustment composed of Adjustment A + Insulin (Adjustment $B$ ) was considered. The contribution of each variable to the model's sum of squares was calculated using sequential sums of squares [9].

\section{Results}

The average age in our sample was 54.9 years $( \pm 2.8)$, the average BMI was $26.5 \mathrm{~kg} / \mathrm{m}^{2}( \pm 3.3)$ and the average SBP was $134 \mathrm{mmHg}( \pm 19)$. Thirty percent of the subjects drank $40 \mathrm{~g} / \mathrm{d}$ of alcohol or more (while $18 \%$ were teetotallers). The concentrations of lipids and of sex hormones were within the normal ranges: average HDL-C: $1.29 \mathrm{mmol} / \mathrm{l}( \pm 0.30)$, average LDL-C: $3.71 \mathrm{mmol} / \mathrm{l}( \pm 0.75)$, average TT: $15.6 \mathrm{nmol} / \mathrm{l}$ $( \pm 4.7)$, average E2: $61.7 \mathrm{pmol} / \mathrm{l}( \pm 25.3)$ and average SHBG: $25.0 \mathrm{nmol} / \mathrm{l}( \pm 11.7)$. The median insulin level was $9.7 \mathrm{mIU} / 1$.

In Table 1 are summarised the correlations between hormonal parameters and blood lipids in univariate analyses. SHBG and TT were correlated negatively with TG, and positively with HDL-C, and E2 was correlated positively with TG. 
Table 1

Associations between sex hormones markers and plasma lipids and apolipoprotein A1 in univariate analyses

\begin{tabular}{lccc}
\hline & $\begin{array}{l}\text { Testosterone } \\
(\mathrm{nmol} / \mathrm{l})\end{array}$ & $\begin{array}{l}\text { Estradiol } \\
(\mathrm{pmol} / \mathrm{l})\end{array}$ & $\begin{array}{l}\text { SHBG } \\
(\mathrm{nmol} / \mathrm{l})\end{array}$ \\
\hline TG $(\mathrm{mmol} / \mathrm{l})^{\mathrm{a}}$ & $-0.121^{*}$ & $0.119^{*}$ & $-0.216^{* * *}$ \\
HDL-C $(\mathrm{mmol} / \mathrm{l})$ & $0.154^{* *}$ & -0.054 & $0.385^{* * *}$ \\
LDL-C $(\mathrm{mmol} / \mathrm{l})$ & -0.091 & 0.002 & -0.032 \\
ApoA1 $(\mathrm{g} / \mathrm{l})$ & 0.099 & 0.054 & $0.270^{* * *}$ \\
\hline
\end{tabular}

${ }^{a}$ log-transformed.

$*<0.05$.

$* *<0.01$.

$* * *<0.001$.

No association was found between any of these sex hormone markers and LDL-C or Lp(a). SHBG was also associated positively with ApoA1, but TT and E2 were not.

In multivariate analyses, SHBG remained associated with TG after adjustment A (centre of recruitment, age, SBP, BMI, smoking, alcohol intake and physical activity) (Table 2), but not E2. SHBG also remained strongly and positively associated with HDL-C after the same adjustments. Conversely, associations of TT with plasma lipids (TG or HDL-C) didn't remain significant when SHBG was taken into account.

After further adjustment for insulin concentrations (Adjustment B), the relationship between HDL-C and SHBG remained highly significant (Table 3 ), and the whole model accounted for $31.3 \%$ of HDL-C's variation. SHBG was the best single predictor of HDL-C $\left(R^{2}\right.$ associated with SHBG in a simple linear regression: 14.1 , versus $13.1 \%$ for insulin,

Table 2

Associations of plasma lipids with SHBG after Adjustment A

\begin{tabular}{lll}
\hline & $\begin{array}{l}\text { Ln (triglycerides) } \\
(\mathrm{mmol} / \mathrm{l}) \beta(\text { S.E. })\end{array}$ & $\begin{array}{l}\text { HDL-C }(\mathrm{mmol} / \mathrm{l}) \\
\beta(\text { S.E. })\end{array}$ \\
\hline Centre & & \\
$\quad$ Toulouse & Ref. & Ref. \\
Strasbourg & $-0.029(0.070)$ & $0.042(0.043)$ \\
Lille & $-0.187(0.068)^{* *}$ & $0.111(0.041)$ \\
Belfast & $0.243(0.084)^{* *}$ & $-0.047(0.052)^{* * *}$ \\
Age (years) & $0.017(0.009)$ & $-0.001(0.006)$ \\
SBP (mmHg) & $0.003(0.001)$ & $0.001(0.001)$ \\
BMI (kg/m $\left.{ }^{2}\right)$ & $0.027(0.008)^{* *}$ & $-0.027(0.005)^{* * * *}$ \\
Smoking & & \\
No & Ref. & Ref. \\
Yes & $0.004(0.059)$ & $-0.058(0.036)$ \\
Alcohol intake & & \\
Abstainers & Ref. & Ref. \\
$1-39 \mathrm{~g} / \mathrm{d}$ & $0.097(0.073)$ & $0.089(0.045)$ \\
$\geq 40 \mathrm{~g} / \mathrm{d}$ & $0.240(0.079)^{* *}$ & $0.167(0.048)^{* * *}$ \\
Physical activity & & \\
No & Ref. & Ref. \\
Yes & $-0.078(0.069)$ & $0.083(0.042)$ \\
SHBG (nmol/l) & $-0.066(0.023)^{* *}$ & $0.083(0.014)^{* * * *}$ \\
$R^{2}(\%)$ & 20.4 & 28.4 \\
\hline
\end{tabular}

Multiple linear regression models; ${ }^{*} p<0.05 .{ }^{* *} p<0.01 .{ }^{* * *} p<0.001$. ${ }^{* * * *} p<0.0001$. $\beta$ for continuous variables are given for an increment of one unit of the variable considered, except for SHBG, given for an increase of $10 \mathrm{nmol} / \mathrm{l}$. S.E.: standard error. Ref: reference class.
Table 3

Associations of plasma lipids with SHBG after Adjustment B (further adjustment for insulin)

\begin{tabular}{|c|c|c|}
\hline & $\begin{array}{l}\text { Ln (Triglycerides) } \\
\text { (mmol/l) } \beta \text { (S.E.) }\end{array}$ & $\begin{array}{l}\text { HDL-C }(\mathrm{mmol} / \mathrm{l}) \\
\beta \text { (S.E.) }\end{array}$ \\
\hline \multicolumn{3}{|l|}{ Centre } \\
\hline Toulouse & Ref. & Ref. \\
\hline Strasbourg & $-0.036(0.066)$ & $0.045(0.042)$ \\
\hline Lille & $-0.172(0.065)^{* * *}$ & $0.109(0.041)^{* *}$ \\
\hline Belfast & $0.189(0.081)^{*}$ & $-0.022(0.051)$ \\
\hline Age (years) & $0.014(0.009)$ & $0.001(0.005)$ \\
\hline SBP (mmHg) & $0.003(0.001)$ & $0.001(0.001)$ \\
\hline BMI $\left(\mathrm{kg} / \mathrm{m}^{2}\right)$ & $0.010(0.009)$ & $-0.019(0.005)^{* * * *}$ \\
\hline \multicolumn{3}{|l|}{ Smoking } \\
\hline No & Ref. & Ref. \\
\hline Yes & $0.001(0.056)$ & $-0.058(0.036)$ \\
\hline \multicolumn{3}{|l|}{ Alcohol intake } \\
\hline Abstainers & Ref. & Ref. \\
\hline $1-39 \mathrm{~g} / \mathrm{d}$ & $0.103(0.070)$ & $0.100(0.044)^{*}$ \\
\hline$\geq 40 \mathrm{~g} / \mathrm{d}$ & $0.243(0.076)^{* *}$ & $0.179(0.048)^{* *}$ \\
\hline \multicolumn{3}{|l|}{ Physical Activity } \\
\hline No & Ref. & Ref. \\
\hline Yes & $-0.061(0.066)$ & $0.073(0.042)$ \\
\hline \multicolumn{3}{|l|}{ Insulin (mIU/l) } \\
\hline $0-6.9$ & Ref. & Ref. \\
\hline $7-9.6$ & $0.158(0.068)^{*}$ & $0.030(0.043)$ \\
\hline $9.7-13.9$ & $0.150(0.072)^{*}$ & $-0.032(0.046)$ \\
\hline$\geq 14$ & $0.448(0.074)^{* * * * *}$ & $-0.132(0.047)^{* *}$ \\
\hline SHBG (nmol/l) & $-0.046(0.022)^{*}$ & $0.075(0.014)^{* * * * *}$ \\
\hline$R^{2}(\%)$ & 28.7 & 31.3 \\
\hline
\end{tabular}

Multiple linear regression models; $\beta$ for continuous variables are given for an increment of one unit of the variable considered, except for SHBG, given for an increase of $10 \mathrm{nmol} / \mathrm{l}$. S.E.: standard error. Ref.: reference class.

$* p<0.05$.

** $p<0.01$.

*** $p<0.001$.

$* * * * p<0.0001$.

$12.6 \%$ for BMI and 3.6\% for alcohol intake). Fig. 1 shows the contribution of each variable of the HDL-C model using sequential sums of squares, i.e. after adjustment for the contribution of all preceding variables in the model. Adjustment variables like age or recruitment centre were introduced first in the model, followed by well-known contributors of HDL-C (physical activity, BMI, alcohol intake...) and at last insulin and then SHBG. So, SHBG still contributes to explain 5,9\% of total HDL-C's variation after adjustment for the contributions of age, centre, SBP, smoking, physical activity, BMI, alcohol intake and insulin.

Conversely, for TG, further adjustment for insulin (Adjustment B) weakened the association between SHBG and TG (30\% decrease in the $\beta$ value). The best single predictor of $\mathrm{Ln}(\mathrm{TG})$ vas insulin $\left(\mathrm{R}^{2}\right.$ associated with insulin in a simple linear regression: $19.3 \%$, vs $7.7 \%$ for BMI, $5.6 \%$ for centre of recruitment and $4.6 \%$ for SHBG).

The relationships between SHBG and TG or HDL-C were also significant if WHR, instead of BMI, was introduced in the models. When ApoA1 was considered as the dependent variable, the association between SHBG and ApoA1 was also 


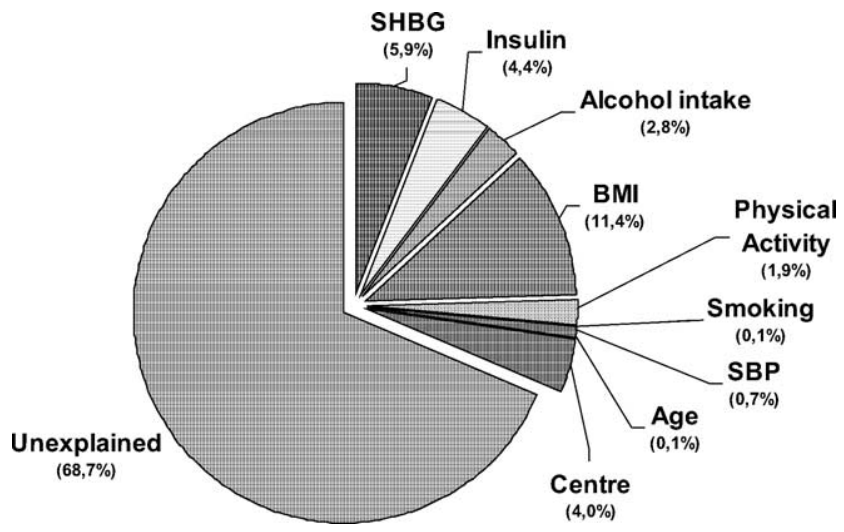

Fig. 1. Contributions of each factor to the total sum of squares of the HDLC's model. The contribution of each variable is conditional on adjustment for all preceding variables beginning with centre (age after adjustment for centre, SBP after adjustment for centre and age..., and finally SHBG after adjustment for centre, age, SBP, smoking, physical activity, BMI, alcohol intake and insulin concentration).

significant after adjustment $\mathrm{A}(\beta=-0.044, p<0.0001)$ and after adjustment $\mathrm{B}(\beta=-0.041, p<0.001)$.

\section{Discussion}

In this work, SHBG was a major determinant of TG and HDL-C, and associations of these plasma lipids with SHBG were much stronger than their associations with sex hormones themselves. Conversely, no association was found between SHBG or sex steroids and LDL-C. To ascertain the reliability of the Planella's formula to compute LDL-C, the results of the Planella's calculation were compared with the results of the Friedewald's formula in subjects with $\mathrm{TG}<4.6 \mathrm{mmol} / \mathrm{l}$. The values of LDL-C obtained with the two different formulas were very similar and the calculation of an intraclass correlation coefficient (enabling the measurement of the resemblance of two calculations) confirmed the very good concordance between these two calculations $\left(r_{\text {intraclass }}=0.98\right)$.

Our results suggest that total levels of steroids might not be an appropriate marker of hormonal activity. TT and SHBG have been found to be related to a beneficial lipid profile (particularly to high HDL-C levels) in men [5,10,11], but free androgens have been associated with an atherogenic lipid profile [10].

These conflicting results might be explained by the fact that the largest part of circulating-testosterone is bound to SHBG. Thus, the measurement of TT might reflect both an atheroprotective effect, which can be explained by its strong association with SHBG, and an atherogenic effect related to free testosterone. However, if free androgens are known to give a better idea of the androgenic activity than TT, the proper role of SHBG should not be underestimated. SHBG has been found to be associated with lipoprotein levels in men [12], being positively related to HDL-C, and low plasma levels of SHBG were found to be a good marker of the metabolic syndrome features [13]. Moreover, according to the National Cholesterol Education Program-Adult Treatment Panel III (NCEP-ATPIII) [14], the metabolic syndrome is defined in men by the presence of any three of the five following abnormalities: waist girth $>102 \mathrm{~mm}$, HDL-C $<1.03 \mathrm{mmol} / \mathrm{l}$, $\mathrm{TG} \geq 1.69 \mathrm{mmol} / \mathrm{l}$, fasting blood glucose $\geq 6.1 \mathrm{mmol} / \mathrm{l}$ and blood pressure $\geq 130 / 85 \mathrm{mmHg}$. We could not adequately use these criteria because fasting glucose concentrations were not available in our study; however, an approximation of this criterion regarding glucose concentration might be obtained using positives answers to two questions from the questionnaire: "Are you following a specific diet for diabetes or risk of diabetes?" and "Have you a treatment for diabetes or risk of diabetes?". Using these questions instead of glucose concentrations to identify subjects with a metabolic syndrome according to NCEP-ATPIII criteria, we found that 60 subjects $(17.1 \%)$ had a metabolic syndrome in our sample, and SHBG concentrations of these subjects were much lower than SHBG concentrations of subjects without metabolic syndrome ( $p<0.0001$, data not shown). Indeed, SHBG seems to play an important role in the hormonal regulation of the lipid profile.

The best known function of SHBG is to regulate the availability of biologically active free testosterone and estradiol and their metabolic clearance rate [15]. Moreover, plasma concentration of SHBG is itself modulated by sex hormones [16], since it is stimulated by estrogens, and inhibited by androgens which thus increase their own bioavailability. Therefore, it is likely that a high level of SHBG would temper the unfavourable effects of free androgens on the lipoprotein profile. Moreover, activity and expression of hepatic lipase, which is involved in HDL-C catabolism [17], is known to be depressed by estradiol but stimulated by androgens $[18,19]$, independently of insulin and abdominal adiposity [19]. Therefore, a high SHBG would result in a decreased free active testosterone, thus maintaining a low hepatic lipase activity and a high level of HDL-C. Although the present study was carried out only among males, it might be speculated that in women, SHBG might also play the same critical role in the free androgens balance. Indeed, a low level of SHBG in women has been found associated with a clinical situation of hyperandrogenism and with features of the metabolic syndrome [20]. Furthermore, it can be hypothesised that SHBG's role in the regulation of the free androgen balance might account to explain a part of the gender difference in CHD incidence, when women usually display a two-fold higher amount of SHBG and a 10-fold lower amount of testosterone than men.

Alternatively, SHBG production is also known to be inhibited by insulin [21-23] and in our work, SHBG remained strongly associated with HDL-C levels, even after adjustment for insulin, while the association of SHBG with TG was weakened by such an adjustment. These results suggest that if SHBG might exert a role in the metabolism of HDL-C, possibly through a regulatory effect on hepatic lipase activity, a large part of the relationship we found between SHBG 
and TG could be explained by the effects of insulin on TG synthesis. Thus, our results add further support to the possible involvement of SHBG in the lipoprotein abnormalities observed in subjects with the metabolic syndrome. Although our study was cross-sectional, SHBG might be considered as a possible determinant of dyslipidaemias occurring in the context of the metabolic syndrome, through an effect partly independent of insulin.

Our data are concordant with the hypothesis that sex hormones and SHBG may influence CHD risk, through their associations with plasma lipids and insulin levels. Also, these results indicate that total levels of sex steroids may not be accurate markers of their hormonal activity. SHBG seems to be a pivotal protein in these relationships, and should be taken into account in further studies on sex hormones and CHD risk or risk factors.

\section{Acknowledgements}

We thank the following organizations which allowed the recruitment of the PRIME subjects: the health screening centers organized by the Social Security of Lille (Institut Pasteur), Strasbourg, Toulouse and Tourcoing; Occupational Medicine Services of Haute-Garonne, of the Urban Community of Strasbourg; the Association Inter-entreprises des Services Médicaux du Travail de Lille et environs; the Comité pour le Développement de la Médecine du Travail; the Mutuelle Générale des PTT du Bas-Rhin; the Laboratoire d'Analyses de l'Institut de Chimie Biologique de la Faculté de Médecine de Strasbourg; the Department of Health (NI) and the Northern-Ireland Chest Heart and Stroke Association.

\section{References}

[1] Lloyd-Jones DM, Larson MG, Beiser A, Levy D. Lifetime risk of developing coronary heart disease. Lancet 1999;353:89-92.

[2] Jousilahti P, Vartiainen E, Tuomilehto J, Puska P. Sex, age, cardiovascular risk factors, and coronary heart disease. A prospective follow-up study of 14,786 middle-aged men and women in Finland. Circulation 1999;99:1165-72.

[3] Kirkland R, Keenan BS, Probstfield JL, et al. Decrease in plasma high-density lipoprotein cholesterol levels at puberty in boys with delayed adolescence. Correlation with plasma testosterone levels. JAMA 1987;257:502-7.

[4] Van der Schouw YT, Van der Graaf Y, Steyerberg EW, Eijkemans JC, Banga JD. Age at menopause as a risk factor for cardiovascular mortality. Lancet 1996;347:714-8.

[5] Alexandersen P, Haarbo J, Christiansen C. The relationship of natural androgens to coronary heart disease in males: a review. Atherosclerosis 1996;125:1-13.

[6] Yarnell JW. The PRIME study: classical risk factors do not explain the severafold differences in risk of coronary heart disease between
France and Northern-Ireland. Prospective epidemiological study of myocardial infarction. QJM 1998;91:667-76.

[7] Luc G, Bard JM, Ferrieres J, et al. Value of HDL cholesterol, apolipoprotein A-I, lipoprotein A-I, and lipoprotein A-I/A-II in prediction of coronary heart disease: the PRIME Study. Prospective epidemiological study of myocardial infarction. Arterioscler Thromb Vasc Biol 2002;22:1155-61.

[8] Planella T, Cortes M, Martinez-Bru C, Gonzalez-Sastre F, OrdonezLlanos J. Calculation of LDL-cholesterol by using apolipoprotein B for classification of nonchylomicronemic dyslipemia. Clin Chem 1997;43:808-15.

[9] Lussier-Cacan S, Xhignesse M, Kessling AM, et al. Sources of variation in plasma lipids and lipoprotein traits in a sample selected for health. Am J Epidemiol 1999;150(11):1229-37.

[10] Gyllenborg J, Rasmussen SL, Borch-Johnsen K, et al. Cardiovascular risk factors in men: the role of gonadal steroids and sex hormonebinding globulin. Metabolism 2001;50:882-8.

[11] Pugeat M, Moulin P, Cousin P, et al. Interrelations between sex hormones-binding globulin (SHBG), plasma lipoproteins and cardiovascular risk. J Steroid Biochem Mol Biol 1995;53:567-72.

[12] Tchernof A, Labrie F, Bélanger A, et al. Relationships between endogenous steroid hormone, sex hormone-binding globulin and lipoprotein levels in men: contribution of visceral obesity, insulin levels and other metabolic variables. Atherosclerosis 1997;133:235-44.

[13] Hajamor S, Després JP, Couillard C, et al. Relationships between sex hormone-binding globulin levels and features of the metabolic syndrome. Metabolism 2003;52:724-30.

[14] Expert panel on detection, evaluation, and treatment of high blood cholesterol in adults. Executive summary of the third report of the National Cholesterol Education Program (NCEP). Expert panel on detection, evaluation, and treatment of high blood cholesterol in adults (adults treatment panel III). JAMA 2001; 285:2486-97.

[15] Rosner W. Plasma steroid-binding proteins. Endocrinol Metab Clin North Am 1991;20:697-720.

[16] Anderson DC. Sex hormone-binding globulin. Clin Endocrinol (Oxf) 1974;3:69-96.

[17] Perret B, Mabile L, Martinez L, et al. Hepatic lipase: structure/function relationship, synthesis, and regulation. J Lipid Res 2002;43:1163-9.

[18] Sorva R, Kuusi T, Dunkel L, Taskinen MR. Effects of endogenous sex steroids on serum lipoproteins and postheparin plasma lipolytic enzymes. J Clin Endocrinol Metab 1988;66:408-13.

[19] Desmeules A, Couillard C, Tchernof A, et al. Post-heparin lipolytic enzyme activities, sex hormones and sex hormone-binding globulin (SHBG) in men and women: the HERITAGE family study. Atherosclerosis 2003;171:343-50.

[20] Kumagai S, Kai Y, Sasaki H. Relationships between insulin resistance, sex hormones and sex hormone-binding globulin in the serum lipid and lipoprotein profiles of Japanese postmenopausal women. J Atheroscler Thromb 2001;8(1):14-20.

[21] Plymate SR, Matej LA, Jones RE, Friedl KE. Inhibition of sex hormone-binding globulin production in the human hepatoma (Hep G2) cell line by insulin and prolactine. J Clin Endocrinol Metab 1988;76:275-8.

[22] Pasquali R, Casimirri F, De Iasio R, et al. Insulin regulates testosterone and sex hormone-binding globulin concentrations in adult normal weight and obese men. J Clin Endocrinol Metab 1995;80:654-8.

[23] Lewis JG, Shand BI, Elder PA, Scott RS. Plasma sex hormonebinding globulin rather than corticosteroid-binding globulin is a marker of insulin resistance in obese adult males. Diab Obes Metab 2004;6:259-63. 